\title{
Physician adherence to hypertension treatment guidelines and drug acquisition costs of antihypertensive drugs at the cardiac clinic: a pilot study
}

\author{
This article was published in the following Dove Press journal: \\ Patient Preference and Adherence \\ 27 January 2012 \\ Number of times this article has been viewed
}

\author{
Shaymaa Abdalwahed \\ Abdulameer' \\ Mohanad Naji Sahib' \\ Noorizan Abd Aziz ${ }^{1,2}$ \\ Yahaya Hassan ${ }^{1,2}$ \\ Hadeer Akram Abdul \\ AlRazzaq' \\ Omar |smail \\ 'School of Pharmaceutical Sciences, \\ Universiti Sains Malaysia, \\ I I800 Minden, Penang, Malaysia; \\ ${ }^{2}$ Faculty of Pharmacy, Universiti \\ Teknologi MARA (UiTM), 42300 \\ Puncak Alam, Selangor, Malaysia; \\ ${ }^{3}$ Hospital Pulau Pinang, 10900, \\ Penang, Malaysia
}

\begin{abstract}
Prescribing pattern surveys are one of the pharmacoepidemiological techniques that provide an unbiased picture of prescribing habits. Prescription surveys permit the identification of suboptimal prescribing patterns for further evaluation. The aims of this study were to determine the prescribing trend, adherence of the prescribers to the guideline, and the impact of drug expenditure on drug utilization at the cardiac clinic of Penang Hospital, Malaysia. This was a cross-sectional study. Demographic data of the patients, diagnoses and the drugs prescribed were recorded. The average drug acquisition costs (ADAC) were calculated for each antihypertensive drug class on a daily and annual basis. Adherence to the guideline was calculated as a percentage of the total number of patients. A total of 313 individuals fulfilled the inclusion criteria. The average age of the study population was $59.30 \pm 10.35$ years. The mean number of drugs per prescription in the study was $2.09 \pm 0.78$. There were no significant differences in the demographic data. Antihypertensive drugs were used in monotherapy and polytherapy in $20.8 \%$ and $79.2 \%$ of the patients, respectively. Adherence to the guideline regarding prescription occurred in $85.30 \%$ of the patients. The lowest priced drug class was diuretics and the highest was angiotensin-receptor blockers. In conclusion, the total adherence to the guideline was good; the adherence percentage only slightly decreased with a co-existing comorbidity (such as diabetes mellitus). The use of thiazide diuretics was encouraged because they are well tolerated and inexpensive, and perindopril was still prescribed for diabetic patients since it is relatively cheap (generic drug) and its daily dosage is beneficial.
\end{abstract}

Keywords: prescribing pattern, adherence, antihypertensive, drug expenditure

\section{Introduction}

Cardiovascular disease (CVD) is responsible for one-third of deaths worldwide. ${ }^{1}$ Hypertension is an extremely prevalent risk factor for CVD. It is a common health problem worldwide due to increasing longevity and the prevalence of contributing factors. ${ }^{2,3}$ The Ministry of Health of Malaysia showed that cardiovascular disease is the main cause of death in government hospitals. ${ }^{4}$ Data from the Third National Health and Morbidity Survey of 2006 (NHM 3) ${ }^{5}$ showed that all of the risk factors which lead to the most common chronic diseases in Malaysia had increased in prevalence compared to the last survey in 1996. The prevalence of hypertension (HT) is now 43\% (up from 33\%) in people aged 30 years and older, diabetes mellitus (DM) 14.9\% (up from $8.3 \%$ ) and overweight/obesity has increased in prevalence to $43 \%$ (up from $27 \%$ ). ${ }^{6}$ While an increase in treatment rate has been observed, the control rate is still inadequate.
Correspondence: Shaymaa Abdalwahed Abdulameer

School of Pharmaceutical Sciences

Universiti Sains Malaysia,

I 1800 Minden Penang, Malaysia

Tel +60146035422

Fax +6 046570017

Email xbm2004@yahoo.com 
According to NHM 3 and the Institute of Health Management of the Ministry of Health on the outpatient management of hypertension in government clinics data, only $26 \%-28.5 \%$ of patients with hypertension who were receiving drug treatment achieved their target blood pressure (BP).

Prescribing pattern surveys are one of the pharmacoepidemiological techniques that provide an unbiased picture of prescribing habits. Prescription surveys permit the identification of suboptimal prescribing patterns for further evaluation. Published guidelines help in clinical decision making, decrease practice variations, guide correctness, and measure the quality of health care. ${ }^{7,8}$ Many studies have connected poor blood pressure control with poor adherence to hypertension guidelines. ${ }^{9-15}$ In addition to the importance of guideline adherence, the drug expenditure plays a role in treatment decisions since many new, expensive drugs are being prescribed at an increasing rate. ${ }^{16} \mathrm{~A}$ study performed by Salman et al in 1999 indicated that knowledge of drug costs has an effect on physician prescription patterns, which is a fact that could lead to appreciable savings in drug costs by prescribers. ${ }^{17}$ Non-compliance to the guidelines may increase risk factors and other complications. Several studies used either prescription or drug dispensing data to evaluate guideline adherence worldwide, but few data are available in Malaysia, which has heterogeneous ethnic groups. This study evaluated physicians' prescribing patterns of antihypertensive drugs, their compliance towards the recommended guideline and compared the costs of antihypertensive drugs based on the recommended guideline.

\section{Methods and study design}

This was a cross-sectional study conducted in the cardiology outpatient clinic of Penang General Hospital for 4 months in 2008, after approval was obtained from the Ministry of Health Ethical Committee MREC (Medical Research Ethics Committee) and from the Penang General Hospital ([PGH] Penang, Malaysia). Demographic data, diagnoses and drug prescriptions were gathered from medical records of patients who attended the outpatient clinic during the study and received antihypertensive therapy for 5 years. The hypertensive patients were divided into two groups (primary hypertension and hypertension with associated clinical conditions) according to a risk assessment using World Health Organization/International Society of Hypertension (WHO/ISH) guidelines for the management of hypertension. ${ }^{18}$ The inclusion criteria of this study were all primary hypertensive patients and hypertensive patients with a comorbidity (diabetes mellitus and ischemic heart disease) who visited the outpatient clinic and were $>18$ years old. The exclusion criteria were all hypertensive patients with renal disease, thyroid disease, heart failure, liver disease, coronary obstructive airway disease, myocardial infarction or patients who have undergone operative revascularization of the coronary vessels and patients with no clear diagnosis or laboratory data.

The antihypertensive drugs were classified into six therapeutic drug classes: $\beta$-blockers (BB), calcium-channel blockers (CCB), diuretics (D), angiotensin-converting enzyme inhibitors (ACEI), angiotensin-receptor blockers (ARB) and other antihypertensive agents $\left(\alpha_{1}\right.$-blockers, central $\alpha_{2}$-agonists, and direct vasodilators). Monotherapy was defined as the use of one antihypertensive drug with only one active ingredient. Patients who were taking more than one active ingredient, either in one combination (except for a combination of two diuretics, such as Moduretic ${ }^{\circledR}$, First DataBank Inc, South San Francisco, CA) or as two different, single pills were defined as receiving polytherapy. ${ }^{19}$ The drug costs were obtained from the pharmacy department (Penang General Hospital).

The average drug acquisition costs (ADAC, the costs of buying the drugs) were calculated for each drug class on a daily and annual basis and the percentage expenditure cost $(\% \mathrm{EC})$ was also calculated, using the following equations. ${ }^{20}$

ADAC (daily) $=$ Total daily cost of drug class/Number of prescriptions of the drug class (multiplied by 365 for the annual basis).

$\% \mathrm{EC}=($ Expenditure cost $(\mathrm{EC})$ of the class/Total expenditure of all prescriptions) $\times 100$

Adherence to the guideline (Management of Hypertension, Academy of Medicine of Malaysia, Jalan Tun Razak, Kuala Lumpur) was calculated as a percentage of the total number of patients. $^{21,22}$ The percentages were calculated as follows:

1. The first step was to specify the treatment guideline for each group of patients:

a. Essential HT (use of D or BB as a first-line therapy or added onto another drug therapy).

b. HT + DM (use of an ACEI or ARB as a first-line therapy or added onto another antihypertensive drug therapy).

c. HT + IHD (use of a BB or CCB as a first-line therapy or added onto another antihypertensive drug therapy).

d. HT + IHD + DM (use of an ACEI or ARB and BB or CCB as a first-line therapy or added onto another antihypertensive drug therapy).

2. The second step was to calculate the percentage of adherence $(\% \mathrm{~A})$ to the guideline:

$\% \mathrm{~A}=($ Total number of cases that followed the guideline/total number of patients) $\times 100$ 
The expenditure per prescription for each diagnosis group (adherence and non-adherence to treatment guideline) was the total of the average expenditure for each drug class used in the treatment of related diagnoses.

\section{Statistical analysis}

The data were processed and presented using the SPSS 15.0 statistical program software (IBM Corporation, Armonk, NY). Independent $t$-tests, Chi-square, ANOVA and Mann-Whitney U tests were used when appropriate to compare the differences between drug group utilization, age groups, gender, race, ADAC and adherence to the guidelines.

\section{Results and discussion Demographic characteristics and prescribing pattern}

Out of 500 patients with hypertension, only 313 individuals fulfilled the inclusion criteria. The data was expressed as mean \pm standard deviation (SD). The demographic data are shown in Table 1.

In our results, 51 patients (16.29\%) had essential hypertension, $32(10.22 \%)$ had hypertension with diabetes mellitus type 2 (DM), 122 (38.97\%) had hypertension with ischemic heart disease (IHD), and 108 (34.50\%) had hypertension with IHD and DM. The average age of the study population was $59.30 \pm 10.35$ years old. There was a significant difference between the average ages of males $(58.21 \pm 10.20)$ and females $(61.86 \pm 10.32)(P<0.01, t(2.877)=311 ; P=0.004)$, which is similar to the findings of a previous study in Malaysia. ${ }^{22}$ The mean age of Malay patients was the lowest compared to the mean age of the other races. There was a significant difference between the mean ages of the different races $(F(3,309)=6.12$; $P<0.001)$. Most of the patients $(69.96 \%)$ were below 65 years

Table I The demographic characteristics of 313 hypertensive patients

\begin{tabular}{|c|c|c|c|}
\hline & Male (\%) & Female (\%) & All patients (\%) \\
\hline Gender (\%) & $219(70)$ & $94(30)$ & $313(100)$ \\
\hline \multicolumn{4}{|c|}{ Age group (years) ${ }^{\dagger}$} \\
\hline$<65$ & $163(74.4)$ & $56(59.6)$ & $219(69.96)$ \\
\hline$\geq 65$ & $56(25.6)$ & $38(40.4)$ & $94(30.03)$ \\
\hline $\begin{array}{l}\text { Mean age in } \\
\text { years }( \pm S D)^{\ddagger}\end{array}$ & $58.21( \pm 10.20)$ & $61.86( \pm 10.32)$ & $59.3( \pm 10.35)$ \\
\hline Median (years) & 57.00 & 62.00 & 58.0 \\
\hline \multicolumn{4}{|l|}{ Race } \\
\hline Malay & $84(26.8)$ & $30(9.6)$ & II4 (36.4) \\
\hline Chinese & $70(22.4)$ & $42(13.4)$ & $112(35.8)$ \\
\hline Indian & $61(19.5)$ & $21(6.7)$ & $82(26.2)$ \\
\hline Others & $4(1.3)$ & $\mathrm{I}(0.3)$ & $5(1.6)$ \\
\hline
\end{tabular}

Notes: ${ }^{+X^{2}}=6.907, \mathrm{df}=1 ; P=0.009 ;{ }^{\dagger} t(2.877)=311 ; P=0.004$. of age. The percentages of Malay and Chinese hypertensive patients were approximately equal (36.4\% Malay, 35.8\% Chinese). This result is inconsistent with the findings of a previous study which showed that Chinese patients had the greatest prevalence of hypertension (30.6\%), followed by Malays (26.7\%) and Indians (25.1\%). ${ }^{23}$ The reason for this could be due to the fact that the sample size in our study was smaller compared to the study by Rampal et al or because the prevalence of hypertension in Penang State needs to be reassessed, which was not covered by Rampal et al or our study. ${ }^{23}$

A total of 655 antihypertensive drugs were prescribed by the physicians. The mean number of drugs per prescription in this study was $2.09 \pm 0.78$, which is fewer than the values reported in studies in developing countries (2.2-3.8 drugs per prescription) such as Jordan, Yemen, Nigeria and Iran..$^{19,24-27}$ However, this value is somewhat similar to values found in developed countries (1.3-2.2 drugs per prescription), ${ }^{28}$ which gives an indication that the Malaysian health prescribing pattern is comparable to patterns in developed countries. No significant difference was found between the mean number of antihypertensive drugs prescribed in males $(2.04 \pm 0.77)$ and females $(2.20 \pm 0.83),(P>0.05, t(1.604)=311 ; P=0.123)$. This result is inconsistent with the results reported by other investigators. ${ }^{29,30}$ Other researchers reported that, compared with men, women used more medicines and requested treatment more frequently. ${ }^{25,27,31-33}$ No significant difference was found between the age groups (younger than 65 and older than $65 ; 2.05 \pm 0.72$, and $2.18 \pm 0.92$, respectively, $(P>0.05$, $t(1.29)=311 ; P=0.243)$ regarding the mean number of antihypertensive drugs per prescription. The same result was reported by Sepehri et al in 2008 in Iran. ${ }^{19}$ The frequency of use of the six antihypertensive drug classes in relation to gender, age, and race is shown in Table 2.

Table 2 The prescription frequency of the six antihypertensive drug classes by cardiologists in hypertensive patients according to gender, age and race

\begin{tabular}{|c|c|c|c|c|c|c|c|}
\hline \multirow[t]{2}{*}{ Drug classes } & \multicolumn{2}{|l|}{ Sex (\%) } & \multicolumn{2}{|c|}{ Age (\%) } & \multicolumn{3}{|c|}{ Race (\%) } \\
\hline & Female & Male & $<65$ & $\geq 65$ & M & C & I \\
\hline $\mathrm{BB}$ & 84.0 & 86.8 & 85.4 & 87.2 & 87.7 & 89.3 & 78.0 \\
\hline $\mathrm{CCB}$ & 20.2 & 19.2 & 16.9 & 25.5 & 14.9 & 17.9 & 26.8 \\
\hline$\left.A C E\right|^{t+\neq}$ & 67.0 & 70.3 & 75.3 & 24.7 & 78.1 & 62.5 & 67.1 \\
\hline$D^{*}$ & 18.7 & 36.2 & 21 & 30.9 & 28.1 & 20.5 & 20.7 \\
\hline $\mathrm{ARB}^{\dagger}$ & 10.6 & 7.3 & 5 & 16 & 3.5 & 12.5 & 7.8 \\
\hline $\begin{array}{l}\text { Others } \\
\text { (prazocin) }\end{array}$ & 5.3 & 3.2 & 2.7 & 6.4 & 0.9 & 7.1 & 3.7 \\
\hline
\end{tabular}

Notes: 'Significant result in respect to age; ¥significant result in respect to race; *significant result in respect to sex; significance level $(P<0.05)$.

Abbreviations: M, Malaysian; C, Chinese; I, Indian; ACEl, angiotensine-converting enzyme inhibitors; $A R B$, angiotensine-receptor blockers; $B B$, $\beta$-blocker; $C C B$, calcium-channel blockers; D, diuretic. 
Only diuretics were used significantly more in males than females. This result is supported by the previous finding that male patients who had a higher relative incidence of coronary arterial disease received more diuretics than females in the treatment of hypertension. ${ }^{34}$ Regarding the age groups, there were no significant differences in terms of the frequency of prescribing $\mathrm{CCB}$ and $\mathrm{BB}$ between the younger and older patients. This pattern is inconsistent with the results of a previous study where geriatric patients were less frequently prescribed BB. This was because adverse drug effects such as fatigue and postural hypotension are more common in older patients treated with $\mathrm{BB}$ agents, and older subjects also seem to respond less well to such agents. ${ }^{35}$ Moreover, elderly patients appear to have a good blood pressure response to calcium-channel blockers, most likely due to their low renin levels and salt status. ${ }^{36-38}$ Consequently, it is important to follow the recommendation of prescribing $\mathrm{BB}$ to younger patients and CCB to elderly patients. Regarding the use of ACEI, the results showed a highly significant difference between the age groups, with the highest frequency of use of this drug class in younger patients. This is because many patients who are at higher risk of cardiovascular events, as well as ACEI, have been shown to reduce morbidity and mortality. ${ }^{39}$ Diuretics are recommended for use in older patients; ${ }^{40}$ however, in our study the elderly patients had a higher frequency for using it.

Only ACEI and ARBs showed significant differences in the prescription percentages between the different racial groups, which may have been due to the side effects of ACEI. It was previously reported that relatively more incidences of ACEI causing cough were found in Chinese (44\%) patients compared to Caucasian patients, which may explain the high percentage of ARB usage in Chinese patients. ${ }^{41}$ No significant difference was found in the mean number of antihypertensive drugs prescribed between the different racial groups $(P>0.05, F(3,309)=2.46$; $P=0.063)$. Antihypertensive drugs were used as monotherapy and polytherapy in $20.8 \%$ and $79.2 \%$ of the patients, respectively. The percentage of monotherapy was lower than found in a previous study in Malaysia 2005. ${ }^{6}$ The dosage strength and frequency of drugs in both monotherapy and polytherapy in our study and the previous study were within the lowest range of the usually recommended therapeutic doses. Rashid estimated that $81 \%$ of patients with hypertension in Malaysia were prescribed only one anti-hypertensive medication and that many of these patients were given suboptimal doses, ${ }^{6}$ which could explain the incidence of uncontrolled hypertension in many patients in Malaysia. Patients on combination therapy (particularly combinations comprising diuretics) are probably more likely to attain the target blood pressure than patients who are on monotherapy or combination therapy without diuretics.

Physicians in Malaysia were found to prescribe drugs at a lower dosage than is prescribed in Western countries. This was thought to be due to the fact that Malaysian people generally have a smaller body size than Caucasians, as based on published literature. In addition, evidence has shown that Asian populations also absorb certain drugs better than Caucasians. Nevertheless, there is no evidence to prove that the response to pharmacotherapy in Asians differs from that of Caucasians. ${ }^{6}$ The antihypertensive medications most frequently used in the cardiology outpatient clinic of Penang Hospital, Malaysia, are shown in Table 3.

\section{Prescribing pattern and prescriber adherence of antihypertensive drugs in patients with essential hypertension}

There were only 51 (16.29\%) patients who had essential hypertension. The prescribing pattern of these patients was as follows: only 18 (35.3\%) were on monotherapy

Table 3 The antihypertensive medications most frequently used in the cardiology outpatient clinic of Penang General Hospital, Malaysia

\begin{tabular}{|c|c|c|c|}
\hline Drug group & Name of drug & Frequency & Percentage \\
\hline \multirow[t]{6}{*}{ BB } & & 269 & 85.9 \\
\hline & Atenolol & 39 & 12.5 \\
\hline & Metoprolol & 209 & 66.8 \\
\hline & Carvedilol & 8 & 2.6 \\
\hline & Bisoprolol & II & 3.5 \\
\hline & Propranolol & 2 & 0.6 \\
\hline \multirow[t]{4}{*}{ ACEI } & & 218 & 69.6 \\
\hline & Enalapril & 32 & 10.2 \\
\hline & Captopril & 13 & 4.2 \\
\hline & Perindopril & 173 & 55.3 \\
\hline \multirow[t]{4}{*}{ Diuretic } & & 75 & 24 \\
\hline & Hydrochlorothiazide & 32 & 10.2 \\
\hline & Furosemide & 40 & 12.8 \\
\hline & $\begin{array}{l}\text { Hydrochlorothiazide/ } \\
\text { amiloride }\end{array}$ & 3 & 1 \\
\hline \multirow[t]{5}{*}{ ARB } & & 25 & 7.9 \\
\hline & Losartan & 7 & 2.2 \\
\hline & Telmisartan & 14 & 4.5 \\
\hline & Valsartan & 3 & I \\
\hline & Irbisartan & I & 0.3 \\
\hline \multirow[t]{4}{*}{$\mathrm{CCB}$} & & 59 & 18.8 \\
\hline & Amlodipine & 23 & 7.3 \\
\hline & Nifedipine & 3 & 1 \\
\hline & Diltiazem & 33 & 10.5 \\
\hline \multirow[t]{2}{*}{ Others } & & 12 & 3.8 \\
\hline & Prazocin & 12 & 3.8 \\
\hline
\end{tabular}

Abbreviations: $B B, \beta$-blocker; $A C E I$, angiotensin-converting enzyme inhibitors; $A R B$, angiotensin-receptor blockers; $C C B$, calcium-channel blockers. 
and $33(64.7 \%)$ were on polytherapy. The most frequently prescribed drug regimen was two-drug therapy (47.1\%). BBs were the most common ditherapy drugs used in combination in these patients $(\mathrm{N}=41,80.4 \%)$, followed by ACEI, $(\mathrm{N}=27,52.9 \%)$ and diuretics $(\mathrm{N}=14,27.5 \%)$, while ARBs and CCB consist only ( $\mathrm{N}=7,13.7 \%)$ for each and the least commonly used drug class was alphablockers $(\mathrm{N}=1,2 \%)$. The drug class most frequently used in monotherapy was also $\mathrm{BB}(\mathrm{N}=12,66.7 \%)$, and the drug class used the least was diuretics $(\mathrm{N}=1,5.6 \%)$. For the two-drug regimen, the most common prescription combination was a $\mathrm{BB}$ and $\mathrm{ACEI}(\mathrm{N}=13,54.2 \%)$, and the least common one was a BB and $\mathrm{CCB}(\mathrm{N}=1,4.2 \%)$. BB were found in about $83.3 \%$ of all two-drug combinations, while diuretics were only found in about $20.83 \%$. The frequency of diuretics prescribed in this study was very low, despite them being recommended in treatment guidelines, which is supported by many randomized, long-term, controlled clinical trials that showed a reduction in both cerebrovascular and cardiovascular morbidity. Diuretics should be used as first-line therapy for most patients with hypertension, either alone or in combination with one of the other classes (ACEI, ARB, BB, CCB). ${ }^{34,39,42}$

In spite of national recommendations, the use of diuretics has gradually reduced over the past 15 years. The reasons for this include the rapid advancement of other medications and the perception that diuretics produce adverse metabolic effects and do not decrease CVD events. However, available data suggest that: (1) alterations in glucose and cholesterol metabolic processes are minor, particularly with the smaller doses now being used; (2) diuretics reduce the rates of morbidity and mortality from cardiovascular diseases in hypertensive patients, even in those with hyperlipidemia or diabetes; and (3) fears about hypokalemia-induced arrhythmias have been exaggerated. ${ }^{43}$ Although there was a high percentage of adherence to the guideline (86.27\%) (Table 4) due to the high percentage of BB use in patients, strong, high quality, evidence exists favouring the use of low-dose thiazide diuretics in the treatment of hypertension in order to reduce blood pressure and rates of cardiovascular disease and death. ${ }^{42}$

\section{Prescription pattern and prescriber adherence in patients with hypertension and diabetes mellitus}

There were $32(10.22 \%)$ patients who had coexisting hypertension and type 2 DM. Eight patients (25\%) were on a single agent, which is lower than recommended since,
Table 4 Total adherence to the prescription guidelines by physician in the outpatient clinic

\begin{tabular}{llll}
\hline $\begin{array}{l}\text { Category (no of } \\
\text { prescriptions) }\end{array}$ & $\begin{array}{l}\text { No of cases } \\
\text { not following } \\
\text { guideline }\end{array}$ & $\begin{array}{l}\text { No of cases } \\
\text { following } \\
\text { guideline }\end{array}$ & $\begin{array}{l}\text { Adherence } \\
\text { (\%A) }\end{array}$ \\
\hline Essential HT (5I) & 7 & 44 & 86.27 \\
HT + DM (32) & 7 & 25 & 78.13 \\
HT + IHD (I22) & 6 & 116 & 95.08 \\
HT + DM + IHD (I08) & 26 & 82 & 75.92 \\
Total adherence (\%A) & $/$ & $/$ & 85.30
\end{tabular}

Abbreviations: DM, Diabetes mellitus; IHD, ischemic heart disease; HT, hypertension.

regardless of the target $\mathrm{BP}$ level; a tight control of $\mathrm{BP}$ is important for reducing CVD mortality and morbidity rates. ${ }^{44}$ In order to reach the target BP in diabetics, two or more drugs are generally required. ${ }^{45}$ Monotherapy with ACE inhibitors was prescribed in $72 \%$ of patients with type $2 \mathrm{DM}$, which is inadequate depending on the evidence trial. ${ }^{44,46}$ ACE inhibitors are recommended because they are known to enhance insulin sensitivity and slow down the progression of diabetes, ${ }^{44,47}$ and ACEI also have the ability to slow down the progression of nephropathy in type 2 diabetes compared to other antihypertensive drugs. ${ }^{48,49}$ Similar to ACEI, ARBs have advantageous effects in slowing down the progression of diabetes, and they also possess the other cardiovascular and renal benefits found with ACEI. ${ }^{50}$ The percentage of adherence to the guideline was $78.13 \%$ (Table 4 ), which showed that the prescribing trends of patients with DM need to be reassessed.

\section{Prescription pattern and prescriber adherence in patients with hypertension and ischemic heart disease}

There were 122 patients (38.97\%) who had hypertension with IHD. The most frequent drug regimen used was the combination of an ACEI and BB (82.66\%). The prescribing frequency of $\mathrm{BB}$ was high $(89.3 \%)$. According to the guideline, BB are the first drugs of choice for the treatment of hypertension in patients with $\mathrm{CAD}{ }^{34,39,51,52}$ On the other hand, CCB should be substituted for BB when BP remains elevated or angina persists or there are adverse side effects or if contraindicated. ${ }^{53}$ According to all of the above evidence and in relation to the prescribing pattern in this group of patients, it was found that the clinicians followed the recommendations of the Malaysian guidelines, with a high percentage of adherence of $95.08 \%$ (Table 4). 
Table 5 Drug acquisition (daily and annual) costs of the different antihypertensive drugs prescribed in the outpatient clinic

\begin{tabular}{|c|c|c|c|}
\hline \multirow[t]{2}{*}{ Drug classes } & \multicolumn{2}{|c|}{$\begin{array}{l}\text { Average drug } \\
\text { acquisition cost per } \\
\text { prescription (RM) }\end{array}$} & \multirow[t]{2}{*}{$\begin{array}{l}\% \text { of class } \\
\text { expenditure } \\
\text { cost }\end{array}$} \\
\hline & Per day & Per year & \\
\hline$\overline{B B}$ & 0.205 & 74.82 & 30.03 \\
\hline ACEI & 0.225 & 82.12 & 26.47 \\
\hline ARB & 1.191 & 434.71 & 16.22 \\
\hline $\mathrm{CCB}$ & 0.718 & 262.07 & 23.46 \\
\hline Diuretics & 0.05 & 18.25 & 2.02 \\
\hline Others (prazocin) & 0.27 & 98.55 & 1.78 \\
\hline
\end{tabular}

Abbreviations: $A C E l$, angiotensin-converting enzyme inhibitors; ARB, angiotensinreceptor blockers; $\mathrm{BB}, \beta$-blocker; $\mathrm{CCB}$, calcium-channel blockers; RM, Malaysian Ringgit (equal approximately to 0.30 USD)

\section{Prescription pattern and prescriber adherence in patients with hypertension, ischemic heart disease and diabetes mellitus} There were 108 cases $(34.5 \%)$ with hypertension, IHD and DM; of these, 96 patients $(88 \%)$ were on polytherapy and the remaining patients were on monotherapy $(11.1 \%)$. The most frequently prescribed drug class by physicians for this group of patients was BB (88\%), followed by ACEI (73.1\%) and their combination (37\%). As previously discussed for patients with DM, this patient population normally requires two or more hypertensive agents for BP treatment, involving ACEI as a first-line treatment with BB for the treatment of IHD. In this study, $58.33 \%$ of the patients received BB as monotherapy. Therefore, the level of success in achieving the target BP, besides good glycemic control, is questionable in Malaysian populations. ${ }^{6}$ The percentage of adherence to the guideline was $75.92 \%$ (Table 4 ), which indicates that the prescribing pattern of this sub-population should be reassessed.

\section{Antihypertensive drug expenditure}

The daily and annual drug acquisition costs per prescription (one Malaysian Ringgit (RM) equal approximately to 0.30 USD) of the various antihypertensive drugs are presented in Table 5.

The ranking in terms of cost from the highest to the lowest was: $\mathrm{ARB}>\mathrm{CCB}>\mathrm{AB}>\mathrm{ACEI}>\mathrm{BB}>\mathrm{D}$. Drug utilization and costs are represented in Figure 1. The antihypertensive cost analysis showed that ARBs accounted for $16.22 \%$ of the total antihypertensive drug costs incurred, although their utilization only represented $7.9 \%$ of the overall antihypertensive drugs. Also, the cost of CCB was high $(23.46 \%)$ in relation to its utilization percentage $(18.8 \%)$ (Figure 1). The explanation of highest cost is that the use of innovator drugs and highest frequency dose for CCB drugs add more cost on drug expenditure per prescription that is available in Penang General Hospital. The cheapest drugs were the diuretics, which can offer some advantages over other drugs used for controlling blood pressure in terms of decreasing cardiovascular morbidity and mortality events. ${ }^{34,39}$ It was not surprising that the expenditure on ACEI out of the total antihypertensive drug expenditure was relatively low because the most commonly used drug of this class was perindopril. The median dosage frequency was about once daily, at the lowest dose strength ( $2 \mathrm{mg}$ ), and it is a generic drug with a low cost. The frequency of metoprolol usage was also high ( $66.8 \%$ out of all BB drugs used) and the median dosage frequency was $50 \mathrm{mg}$ bd. This added additional costs to $\mathrm{BB}$ expenditure compared to the cheapest $\mathrm{BB}$, atenolol. However, the use of thiazides as a first-choice therapy would result in substantial cost savings due to their favourable price. ${ }^{54}$ Thus, the medical profession should release a clear statement: thiazides are the most common agents for the treatment of hypertension due to their effectiveness and lower

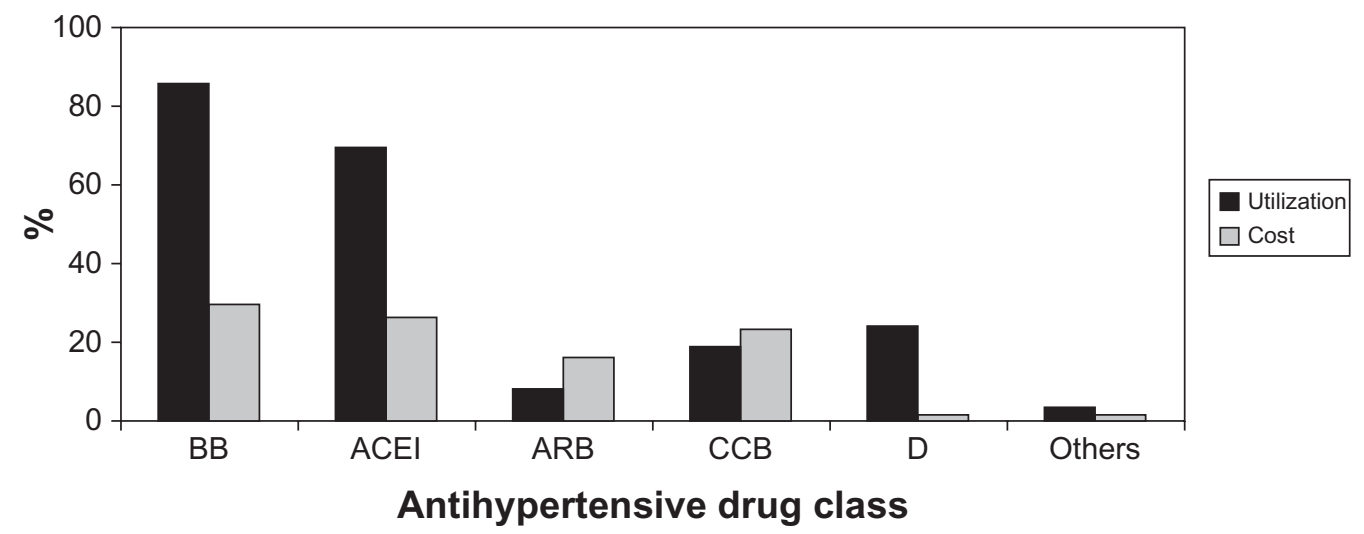

Figure I Utilization and expenditure patterns of antihypertensive drugs in out patient cardiac clinic.

Abbreviations: BB, $\beta$-blocker; ACEI, angiotensine-converting enzyme inhibitors; ARB, angiotensine-receptor blockers; CCB, calcium-channel blockers; $D$, diuretics. 
Table 6 Drug acquisition costs of the different prescriptions for different diagnoses and adherence

\begin{tabular}{llll}
\hline Diagnosis & \multicolumn{3}{l}{$\begin{array}{l}\text { Average drug acquisition cost per } \\
\text { prescription (RM) }\end{array}$} \\
\cline { 2 - 4 } & $\begin{array}{l}\text { Following the } \\
\text { guidelines }\end{array}$ & $\begin{array}{l}\text { Not following } \\
\text { the guidelines }\end{array}$ & $\begin{array}{l}\text { Significance } \\
\text { level }\end{array}$ \\
\hline HT & 0.477 & 0.708 & 0.547 \\
HT + DM & 0.761 & 0.23 & 0.005 \\
HT + IHD & 0.458 & 0.142 & 0.004 \\
HT + IHD + DM & 0.803 & 0.63 & 0.02 \\
\hline
\end{tabular}

Abbreviations: DM, diabetes mellitus; IHD, ischemic heart disease; HT, hypertension; RM, Malaysian Ringgit (equal approximately to 0.30 USD).

cost. ${ }^{55-58}$ The treatment costs of essential hypertension with and without comorbidity are shown in Table 6 .

There were extremely significant differences between the drug costs in each group by both following and not following the guideline for the treatment of hypertension with comorbidity. The results showed a decrease in the treatment costs of hypertension with a coexisting disease in cases where the guidelines were not followed, indicating inadequate treatment. In contrast, for the treatment of essential hypertension, there was an increase in costs in cases where the guidelines were not followed, which indicates that more expensive drugs were prescribed instead of the first-line treatment consisting of cheaper drugs such as diuretics.

\section{Study limitations}

This study did not take into account the blood pressure of each patient; also, the small sample size (as it was a pilot study) did not give a precise picture of the management of hypertension patients. Further investigations are needed to support the results found for these populations.

\section{Conclusion}

The level of adherence to the guidelines is high in Malaysian health-care prescribing patterns, but this percentage decreased with a coexisting disease, especially diabetes mellitus. Thus, the use of thiazide diuretics should be encouraged because they are well tolerated and inexpensive, and several large studies support the use of thiazide diuretics in the treatment of hypertension to reduce cardiovascular clinical events and stroke. In addition, the use of ACEI should be promoted as they have cardio- and renoprotective effects in diabetic patients. Perindopril should continue to be prescribed because it is relatively cheap and its daily dosage is beneficial. Hypertension treatment using diuretics or BBs was more cost-efficient than with ARBs or CCBs. The results of this study also suggest the use of diuretics and
CCBs in the elderly instead of BBs. Finally, the results of this study could help health care planners make better decisions concerning the distribution of funds between medicinal options.

\section{Disclosure}

The authors report no conflicts of interest in this work.

\section{References}

1. Whitworth JA; World Health Organization, International Society of Hypertension Writing Group. 2003 World Health Organization (WHO) International Society of Hypertension (ISH) statement on management of hypertension. J Hypertens. 2003;21(11):1983-1992.

2. Singh RB, Suh IL, Singh VP, Chaithiraphan S, et al. Hypertension and stroke in Asia: prevalence, control and strategies in developing countries for prevention. J Hum Hypertens. 2000;14(10-11):749-763.

3. Yusuf S, Reddy S, Ounpuu S, Anand S. Global burden of cardiovascular diseases: part I: general considerations, the epidemiologic transition, risk factors, and impact of urbanization. Circulation. 2001;104(22):2746-2753.

4. Zambahari R. Trends in cardiovascular diseases and risk factor in Malaysia. International Congress Series. 2004;1262:446-449.

5. Institute of Public Health (IPH). The Third National Health and Morbidity Survey 2006. Volume 2. Ministry of Health Malaysia; 2008:199-316.

6. Rashid AR. Suboptimal treatment in chronic diseases - time to go back to basics. Med J Malaysia. 2008;63(3):185-187.

7. Wagner EH. Chronic disease management: what will it take to improve care for chronic illness? Eff Clin Pract. 1998;1(1):2-4.

8. Bodenheimer T, Wagner EH, Grumbach $\mathrm{K}$. Improving primary care for patients with chronic illness: the chronic care model, Part 2. JAMA. 2002;288(15):1909-1914.

9. Monane M, Glynn RJ, Gurwitz JH, Bohn RL, et al. Trends in medication choices for hypertension in the elderly. The decline of the thiazides. Hypertension. 1995;25(5):1045-1051.

10. Dickerson JE, Garratt CJ, Brown MJ. Management of hypertension in general practice: agreements with and variations from the British Hypertension Society guidelines. J Hum Hypertens. 1995;9(10):835-839.

11. Siegel D, Lopez J. Trends in antihypertensive drug use in the United States: do the JNC V recommendations affect prescribing? Fifth joint national committee on the detection, evaluation, and treatment of high blood pressure. JAMA. 1997;278(21):1745-1748.

12. Asch SM, Kerr EA, Lapuerta P, Law A, et al. A new approach for measuring quality of care for women with hypertension. Arch Intern Med. 2001;161(10):1329-1335.

13. Clause SL, Hamilton RA. Medicaid prescriber compliance with Joint National Committee VI Hypertension Treatment Guidelines. Ann Pharmacother. 2002;36(10):1505-1511.

14. Cuspidi C, Michev I, Lonati L, Vaccarella A, et al. Compliance to hypertension guidelines in clinical practice: a multicentre pilot study in Italy. J Hum Hypertens. 2002;16(10):699-703.

15. Milchak JL, Carter BL, James PA, Ardery G. Measuring adherence to practice guidelines for the management of hypertension: an evaluation of the literature. Hypertension. 2004;44(5):602-608.

16. Ross S, Macleod MJ. Antihypertensive drug prescribing in Grampian. Br J Clin Pharmacol. 2005;60(3):300-305.

17. Salman H, Bergman M, Hart J, Neuman V, et al. The effect of drug cost on hypertension treatment decision. Public Health. 1999;113(5): 243-246.

18. 1999 World health organization-international society of hypertension guideline for the management of hypertension. J Hypertens. 1999;17(2): $151-183$.

19. Sepehri G, Talebizadeh N, Mirzazadeh A, Mohsenbeigi M. The patterns of antihypertensive drug prescription by cardiologists in Kerman province of Iran, 2006. Pharmacoepidemiol Drug Saf. 2008;17(2):180-185. 
20. Jhaj R, Goel NK, Gautam CS, Hota D, et al. Prescribing patterns and cost of antihypertensive drugs in an internal medicine clinic. Indian Heart J. 2001;53(3):323-327.

21. Management of Hypertension. 3rd ed. Academy of Medicine of Malaysia; 2008. http://www.acadmed.org.my/index.cfm?\&menuid=67.

22. Goldstein MK, Lavori P, Coleman R, Advani A, et al. Improving adherence to guidelines for hypertension drug prescribing: cluster-randomized controlled trial of general versus patient-specific recommendations. Am J Manag Care. 2005;11(11):677-685.

23. Rampal L, Rampal S, Azhar MZ, Rahman AR. Prevalence, awareness, treatment and control of hypertension in Malaysia: A national study of 16,440 subjects. Public Health. 2008;122(1):11-18.

24. Hogerzeil HV, Bimo CA, Ross-Degnan D, et al. Field tests for rational drug use in twelve developing countries. Lancet. 1993;342(8884): 1408-1410.

25. Moghadamnia AA, Mirbolooki MR, Aghili MB. General practitioner prescribing patterns in Babol city, Islamic Republic of Iran. East Mediterr Health J. 2002;8(4-5):550-555.

26. Otoom S, Batieha A, Hadidi H, Hasan M, et al. Evaluation of drug use in Jordan using WHO prescribing indicators. East Mediterr Health J. 2002;8(4-5):537-543.

27. Gholamreza-Sepeheri, Meimandi MS. The quality of prescribing in general practice in Kerman, Iran. Int J Health Care Qual Assur Inc Leadersh Health Serv. 2005;18(4-5):353-360.

28. Gu Q, Paulose-Ram R, Dillon C, Burt V. Antihypertensive medication use among US adults with hypertension. Circulation. 2006;113(2): 213-221.

29. Hansson L, Lindholm LH, Ekbom T, et al. Randomised trial of old and new antihypertensive drugs in elderly patients: cardiovascular mortality and morbidity the Swedish trial in old patients with hypertension-2 study. Lancet. 1999;354(9192):1751-1756.

30. Tiwari H, Kumar A, Kulkarni SK. Prescription monitoring of antihypertensive drug utilisation at the Panjab University Health Centre in India. Singapore Med J. 2004;45(3):117-120.

31. Negishi E, Domon Y, Ueda M, Kadowaki K, Ueno K. Surveillance study about the use actual of prescription drugs from the viewpoint of gender. Yakugaku Zasshi. 2005;125(10):821-827. Article in Japanese.

32. Ueno K, Negishi E. Pharmacological gender-specific medicine. Rinsho Byori. 2006;54(1):51-58. Article in Japanese.

33. Sepehri G, Meimandi MS. Pattern of drug prescription and utilization among Bam residents during the first six months after the 2003 Bam earthquake. Prehosp Disaster Med. 2006;21(6):396-402.

34. Chobanian AV, Bakris GL, Black HR, et al. The seventh report of the joint national committee on prevention, detection, evaluation, and treatment of high blood pressure: the JNC 7 report. JAMA. 2003;289(19):2560-2572.

35. Beard K, Bulpitt C, Mascie-Taylor H, O’Malley K, et al. Management of elderly patients with sustained hypertension. BMJ. 1992;304(6824): 412-419.

36. Bühler FR. Age and pathophysiology-oriented antihypertensive response to calcium antagonists. J Cardiovasc Pharmacol. 1988;12(Suppl 8): S156-S162.

37. Black HR. Choosing initial therapy for hypertension. A personal view. Hypertension. 1989;13:I149-I153.

38. Frohlich ED. Calcium antagonists for initial therapy of hypertension. Heart Lung. 1989;18(4):370-376.

39. Ministry of Health Malaysia, Academy of Medicine Malaysia, Malaysian Society of Hypertension. Clinical practice guidelines. Management of hypertension. 3rd ed. CPG Secretariat, Putrajaya, Malaysia; 2008:MOH/P/PAK/156.08(GU). http://www.moh.gov.my.

Patient Preference and Adherence

\section{Publish your work in this journal}

Patient Preference and Adherence is an international, peer-reviewed, open access journal focusing on the growing importance of patient preference and adherence throughout the therapeutic continuum. Patient satisfaction, acceptability, quality of life, compliance, persistence and their role in developing new therapeutic modalities and compounds to
40. Greene RS, Quinones ME, Edwards KL. Evaluation of thiazide diuretic use as preferred therapy in uncomplicated essential hypertension patients. Pharmacy Practice. 2007;5:130-134.

41. Chan WK, Chan TY, Luk WK, Leung VK, et al. A high incidence of cough in Chinese subjects treated with angiotensin converting enzyme inhibitors. Eur J Clin Pharmacol. 1993;44(3):299-300.

42. Psaty BM, Manolio TA, Smith NL, et al. Time trends in high blood pressure control and the use of antihypertensive medication in older adults: the cardiovascular health study. Arch Intern Med. 2002;162(20): 2325-2332.

43. Moser $\mathrm{M}$. Why are physicians not prescribing diuretics more frequently in the management of hypertension? JAMA. 1998;279(22):1813-1816.

44. Whaley-Connell A, Sowers JR. Hypertension management in type 2 diabetes mellitus: recommendations of the Joint National Committee VII. Endocrinol Metab Clin North Am. 2005;34(1):63-75.

45. Arauz-Pacheco C, Parrott MA, Raskin P. The treatment of hypertension in adult patients with diabetes. Diabetes Care. 2002;25(1):134-147.

46. Scheen AJ. Renin-angiotensin system inhibition prevents type 2 diabetes mellitus. Part 1. A meta-analysis of randomised clinical trials. Diabetes Metab. 2004;30(6):487-496.

47. Niklason A, Hedner T, Niskanen L, Lanke J. Development of diabetes is retarded by ACE inhibition in hypertensive patients - a subanalysis of the Captopril Prevention Project (CAPPP). J Hypertens. 2004;22(3): 645-652.

48. Ravid M, Lang R, Rachmani R, Lishner M. Long-term renoprotective effect of angiotensin-converting enzyme inhibition in non-insulindependent diabetes mellitus. A 7-year follow-up study. Arch Intern Med. 1996;156(3):286-289.

49. Bakris GL, Smith AC, Richardson DJ, et al. Impact of an ACE inhibitor and calcium antagonist on microalbuminuria and lipid subfractions in type 2 diabetes: a randomised, multi-centre pilot study. J Hum Hypertens. 2002;16(3):185-191.

50. Miyata T, van Ypersele de Strihou C. Renoprotection of angiotensin receptor blockers: beyond blood pressure lowering. Nephrol Dial Transplant. 2006;21(4):846-849.

51. Gibbons RJ, Abrams J, Chatterjee K, et al. ACC/AHA 2002 guideline update for the management of patients with chronic stable angina summary article: a report of the American College of Cardiology/American Heart Association Task Force on practice guidelines (Committee on the management of patients with chronic stable angina). $J$ Am Coll Cardiol. 2003;41(1):159-168.

52. Rosendorff C, Black HR, Cannon CP, et al. Treatment of hypertension in the prevention and management of ischemic heart disease: a scientific statement from the American Heart Association Council for High Blood Pressure Research and the Councils on Clinical Cardiology and Epidemiology and Prevention. Circulation. 2007;115(21):2761-2788.

53. van Bemmel T, Gussekloo J, Westendorp RGJ, Blauw GJ. In a populationbased prospective study, no association between high blood pressure and mortality after age 85 years. J Hypertens. 2006;24(2): 28-292.

54. Fretheim A, Aaserud M, Oxman AD. The potential savings of using thiazides as the first choice antihypertensive drug: cost-minimisation analysis. BMC Health Serv Res. 2003;3(1):18.

55. Chalmers J. All hats off to ALLHAT: a massive study with clear messages. J Hypertens. 2003;21(2):225-228.

56. Kaplan NM. The meaning of ALLHAT. J Hypertens. 2003;21(2): 233-234.

57. Fagard RH. The ALLHAT trial: strengths and limitations. J Hypertens. 2003;21(2):229-232.

58. Fretheim A. Back to thiazide-diuretics for hypertension: reflections after a decade of irrational prescribing. BMC Fam Pract. 2003;4:19.

\section{Dovepress}

optimize clinical outcomes for existing disease states are major areas of interest. This journal has been accepted for indexing on PubMed Central. The manuscript management system is completely online and includes a very quick and fair peer-review system. Visit http://www.dovepress.com/ testimonials.php to read real quotes from published authors. 